American Journal of Applied Sciences 4 (6): 386-389, 2007

ISSN 1546-9239

(C) 2007 Science Publications

\title{
Design and Development of a Photovoltaic Power System for Tropical Greenhouse Cooling
}

\author{
${ }^{1}$ Faisal Mohammed Seif Al-Shamiry, ${ }^{1}$ Desa Ahmad, ${ }^{1}$ Abdul Rashid Mohamed Sharif \\ ${ }^{2}$ Ishak Aris, ${ }^{1}$ Rimfiel Janius and ${ }^{3}$ Rezuwan Kamaruddin \\ ${ }^{1}$ Biological and Agricultural Engineering Department \\ ${ }^{2}$ Electrical and Electronic Engineering Department, Faculty of Engineering \\ University Putra Malaysia (UPM), 43400 Serdang, Selangor, Malaysia \\ ${ }^{3}$ Mechanization and Automation Research Centre \\ Malaysian Agricultural Research and Development Institute (MARDI)
}

\begin{abstract}
Renewable energy sources like photovoltaic (PV) panels are used today in many applications. Natural ventilation in tropical greenhouse is common method for ventilation, which gives higher inside temperatures compared to the outside temperatures. In addition, this type of ventilation is not enough to reduce high temperature inside the structure in low land areas. Thus the requirement of cooling is increased. Use of the fossil fuel to run the cooling fans are not economically viable due to increasing of fuel cost and greenhouses are not always located near the electrical grid. This research presents a study on the installation and test of a complete photovoltaic hybrid system for cooling a tropical greenhouse. A hybrid photovoltaic system consisting of two photovoltaic sub-systems were connected to each other. This system includes 48 photovoltaic solar Panels with 18.75 watt each, one inverter, 1 charge controller and a battery bank (including 12 batteries). The PV system is located at University Putra Malaysia (UPM) Research Park. The national electricity grid was used as a backup unit. The load consisted of two misting fans for cooling greenhouse (during test period time) with 400 Watt electric power and five hours (11:00 am to $16: 00 \mathrm{pm})$ daily operation. The results obtained showed that the maximum current drawn from the array was found to be 14.9 ampere at 13:00 pm (with load). The voltage of array was found to be 26.9 volt while the voltage and current of battery bank were found to be 26.2 volt and 23.0 ampere respectively. In conclusion, this study highlights the primary study of PV hybrid energy systems for tropical greenhouse cooling as an application of renewable energy in Selangor, Malaysia. The results showed that PV system would be suitable to supply electricity to cover the loads requirement demands without using energy from the grid
\end{abstract}

Key words: Photovoltaic system, greenhouse, cooling system

\section{INTRODUCTION}

Malaysia lies in the tropical region between $1^{\circ} \mathrm{N}$ and $7^{\circ} \mathrm{N}$, and $100^{\circ} \mathrm{E}$ and $119^{\circ} \mathrm{E}$. Malaysia is made up of Peninsular Malaysia and the states of Sabah and Sarawak on the island of Borneo. The climate is hot and humid throughout the year with heavy rainfall. Rainfall range is $2032-2540 \mathrm{~mm}$, temperature $21-32^{\circ} \mathrm{C}$, relative humidity $80-90 \%$, solar radiation $12-20 \mathrm{MJ} / \mathrm{m}^{2}$ and wind speed $2-22 \mathrm{~m} / \mathrm{s}$. There are approximately 6 hours of sunshine per day ${ }^{[1]}$.

Renewable energy plays an increasingly important role in the energy supply of the developing and industrializing countries. Developing a clean and renewable energy has become one of the most important tasks assigned to modern science and engineering. Photovoltaic (device converts sunlight directly into electric energy) energy comes along as the most promising one as a future energy resource.

Ramakumar $^{[2]}$ indicated that the ultimate objective of any design procedure employed is to obtain the sizes and ratings of the various energy conversion and energy storage devices needed to supply energy to different loads.

A hybrid system can be generally defined as an electricity production and distribution system which consists of a combination of two or more types of electricity generating sources (example solar photovoltaic panels and wind turbine generators,). Hybrid systems usually also include an energy storage.

Corresponding Author: Faisal Mohammed Seif Al-Shamiry, Biological and Agricultural Engineering Department, Faculty of Engineering, University Putra Malaysia, 43400 Serdang, Selangor, Malaysia 
Battery provides storage energy, which is delivered at the time the solar radiation is low, in cloudy periods or at night-time. Lead-acid batteries operation is characterized by the limited range of depth of discharge (DOD), the value currently being limited to a maximum of $80 \%$ at the best operating conditions. If this value is exceeded, the battery suffers from over-discharge, and permanent damage may result if the battery remains at this state for long. Armenta-Deu ${ }^{[3]}$ concluded that the state of charge (SOC) has revealed to be an influencing parameter onto the battery voltage evaluation, especially during the charging and overcharging process. The inverter has to be capable of handling the maximum expected power AC loads ${ }^{[4]}$.

AC utility back-up would incorporate an automatic charger wired to the battery bank which would regulate charge when batteries are low and automatically cut off when batteries have sufficient operating power.

The PV energy systems differ from conventional energy systems in that they have high initial and low operating costs, and using PV systems is very important, especially when their life cycle costs are competitive with the other types of conventional energy sources $^{[5,6]}$.

The photovoltaic $(\mathrm{PV})$ module prices have dropped from $\$ 500 / \mathrm{W}$ peak in 1972 to approximately $\$ 4-\$ 5 / \mathrm{W}$ peak in $1990^{[7]}$. Wagdy ${ }^{[8]}$ and Haas ${ }^{[9]}$ have stated that realistic economic analysis of PV systems is difficult to translate into an accurate long-term cost projection because of the number of complex factors involved.

The price of PV system and its installation are important factors in the economics of PV systems. These include the prices of PV modules, storage batteries, the control unit, the inverter, installation and all other auxiliaries. This research presents a study on the installation and test of a complete photovoltaic hybrid system for cooling a tropical greenhouse.

\section{MATERIAL AND METHODS}

Electric load estimation: The load consists of two fans with total power $400 \mathrm{~W}$, each fan $200 \mathrm{~W}$ and $240 \mathrm{VAC}$. The total average daily load is $2.000 \mathrm{kWh} /$ day. Fan consumption at 260 Watts and at $240 \mathrm{VAC}$ through an inverter would require $21.7 \mathrm{Amps} / \mathrm{Hour}$ at $12 \mathrm{VDC}$ load demand with a daily operation of 5 Hours (11:00-16:00) and 3 days autonomy. The total load demand is 217 Amps.

System configuration: The PV system includes 48 photovoltaic solar Panels, one inverter, one charge controller and a battery bank as shown in Fig. 1 and 2. The system is located at University Putra Malaysia (UPM) Research Park. The national electricity grid is used as a backup unit. Each PV panel generates 18.75 $\mathrm{W}_{\mathrm{p}}$ and 1.14 Amps/hours. Therefore to provide electric power for 217 Amps total, 48 PV Modules would be required per subsystem. The total energy generation from 48 Modules (48*1.14Amps/hour*5 hours of sunshine/day) is 273.6 Amps. This energy covers the load demand (217 Amps) consumption and 56.6Amps to further offset weather and inverter efficiency inherent with PV system. Turn-on and Turn-off functions were carried out by means of timer, temperature and humidity sensors.

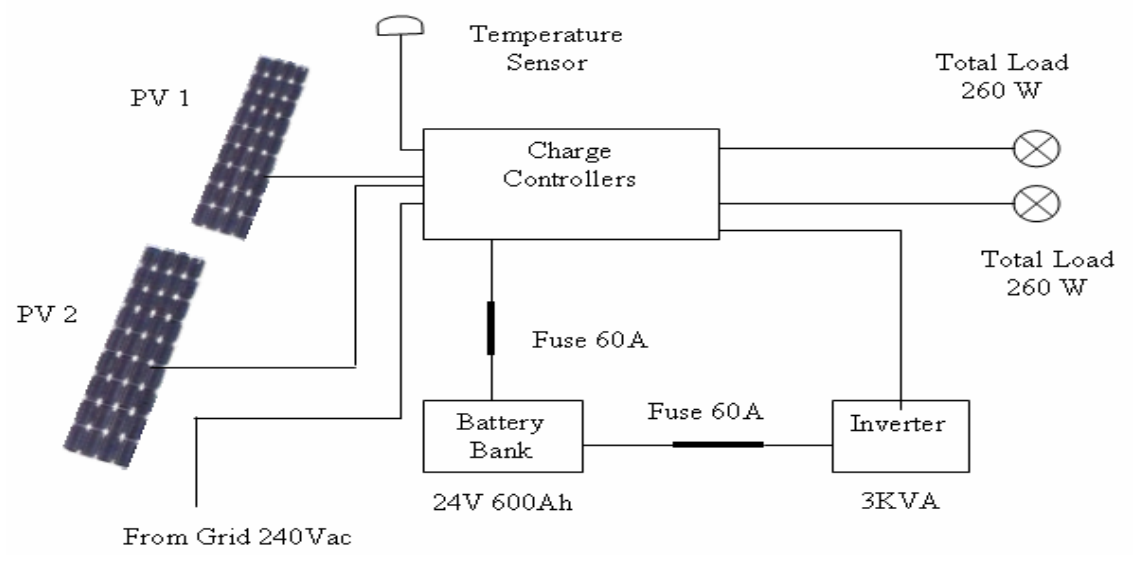

Fig.1: Schematic diagram of the PV energy system 

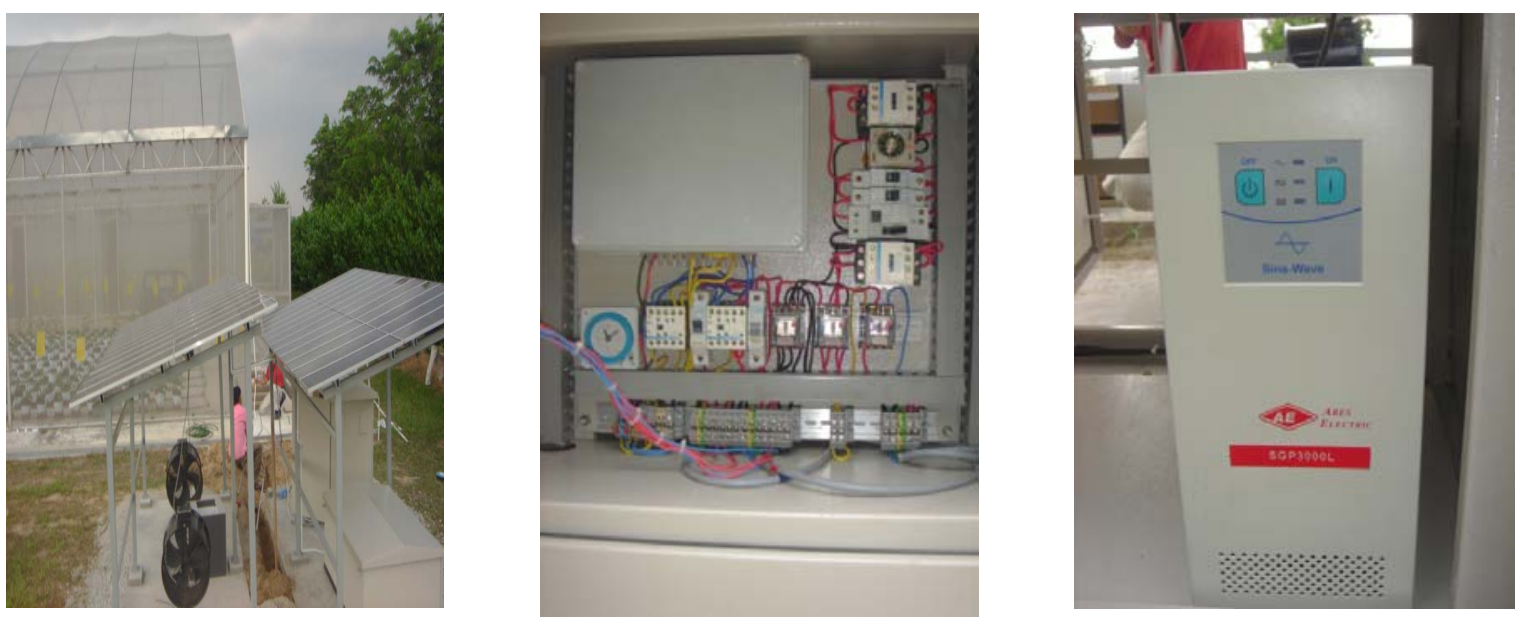

Fig. 2: PV array structure, controller and inverter

The system was turned-on at 11:00 am and turned-off at 16:00 pm by means of the timer sensor. When the inside temperature dropped to $\leq 30^{\circ} \mathrm{C}$ the system could be turned-off. When the temperature reached $>30^{\circ} \mathrm{C}$ the system was turned-on. This process was carried out by means of temperature sensor. When the inside humidity reached $85 \%$ the water supply was stopped by means of water solenoid valve and humidity sensor. Grid is used to charge the battery during cloudy days if battery voltage falls below preset levels in the controller. Change over to Grid will operate in case of total PV system failure.

\section{RESULTS AND DISCUSSION}

PV system: Figure 3 shows the outside and cell temperatures. The cell temperature was found to be $49^{\circ} \mathrm{C}$ while the outside temperature was found to be $36.9^{\circ} \mathrm{C}$ at $14: 00 \mathrm{pm}$. The maximum PV array voltage and current were found to be $26.9 \mathrm{~V}$ and 14.9 Amps while the maximum Battery voltage and current were found to be $26.2 \mathrm{~V}$ and $23 \mathrm{Amps}$ as shown in Fig. 4. Figure 5 shows the daily electric power from PV system. The PV system power was found to be 340.2 Watt at 11:00 am. This value was increased to 400.81 at 13:00 $\mathrm{pm}$ and decreased to $275.6 \mathrm{Watt}$ at 16:00 pm. The total energy per day (from 8:00 am to 6:00 pm), given by the PV modules to the battery bank was $2.8 \mathrm{kWh}$. From the load data, consumption of energy per day was $2.6 \mathrm{kWh}$, which is about $92.86 \%$ of the PV supplied energy.

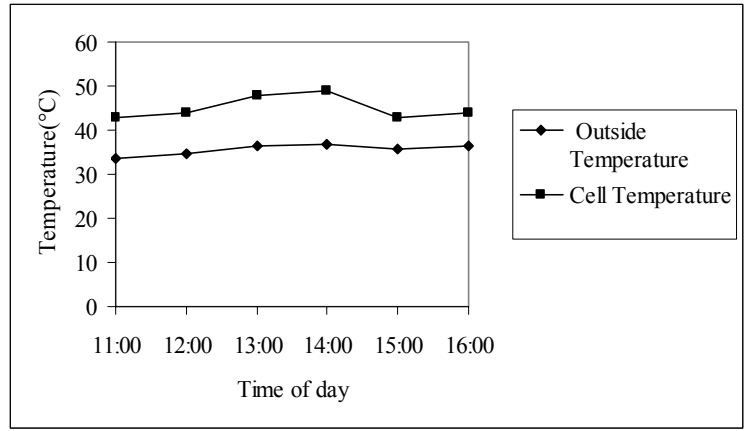

Fig. 3: Outside and cell temperatures

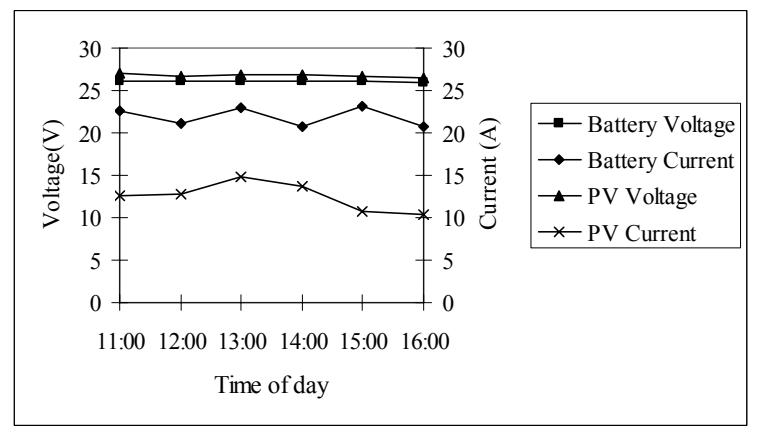

Fig. 4. DC system output

These results show that PV system would be suitable to supply electricity to cover the loads requirement demands without utilizing energy from the electrical grid. 
Am. J. Appl. Sci., 4 (6): 386-389, 2007

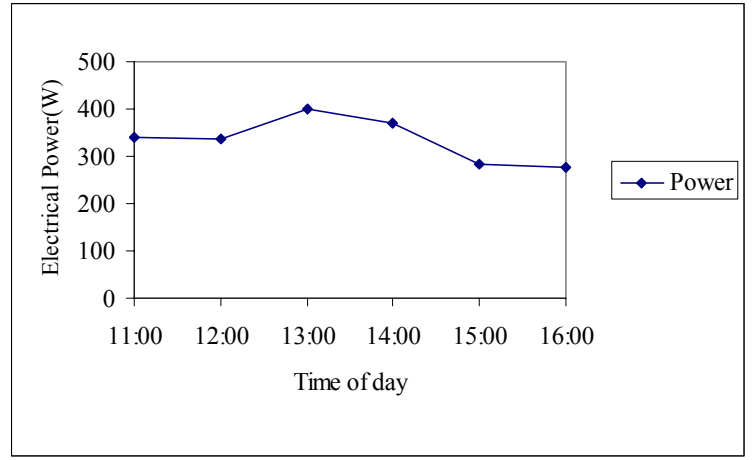

Fig.5: System power

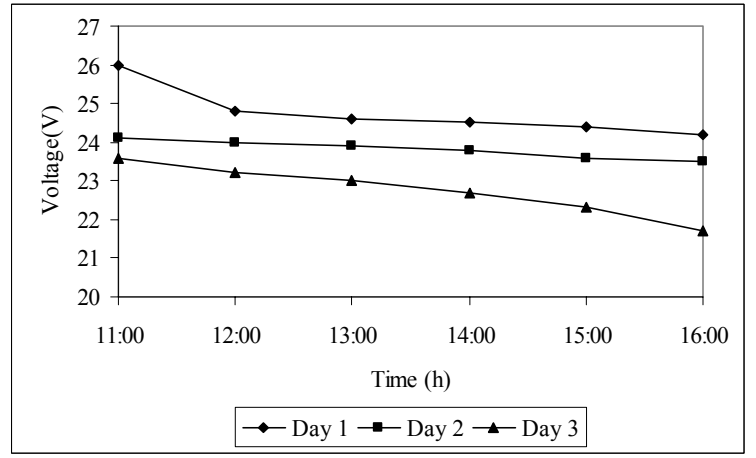

Fig. 6: Battery voltage

Battery test: To test the battery bank, the PV arrays were switched off, that means there is no electric power supply from PV arrays to the battery. The battery bank was sized for 3 days autonomy consisting of 12 batteries of $100 \mathrm{Ah}$ each with total $1200 \mathrm{Ah}$ and the depth of discharge (DOD) of $70 \%$ equivalent to 840 Ah for usage with 3 days autonomy. Figure 6 shows the battery bank voltage against time. The fans were switched on for three days from 11:00 am to 16:00 pm. On the third day and when the battery voltage reduced to $20.9 \mathrm{~V}$ the fans were switched off. The inverter was also switched off and the system was changed to the grid supply system.

\section{CONCLUSION}

The photovoltaic hybrid system for cooling a tropical greenhouse was installed and tested. The evaporative (misting fans) cooling system in real greenhouse was operated with energy generated by PV system. This study shows that the PV system is running satisfactorily. As PV Systems are clean and do not cause pollution of any type during their use while the price of PV decreases every year and their efficiencies and reliability increased, there is a good sign of the practical utilization of this research finding.

\section{ACKNOWLEDGEMENTS}

This project was funded by MOSTI under IRPA Project No. 09-02-04-0873 EA001. The authors are also thankful to the Malaysian Metrological Service (Ministry of Science, Technology \& Innovation).

\section{REFERENCES}

1. Kamaruddin, R., B.J. Bailey and J.I. Montero, 2002. A naturally ventilation Greenhouse for temperate vegetable production in the tropics. Acta Horticulturae, pp: 578.

2. Ramakumar, R.I., Abouzahr and K. Ashenayi, 1992. A knowledge-based approach to the design of integrated renewable energy system, IEEE Transaction on Energy Conversion, 7: 648-659.

3. Armenta-Deu, C. 2003. Prediction of battery behaviour in SAPV applications. Renewable Energy 28: 1671-1684.

4. Wenham, S.R., M.A.Green and M.E.Watt, 1994. Applied photovoltaics. Australia: Center for Photovoltaic Devices and Systems.

5. Ahmad, G.E., 2002. Photovoltaic-powered rural zone family house in Egypt, renewable energy, 26: 379-390.

6. Dakak, M., A. Hirata, R. Muhida and Z. Kawasaki, 2003. Operation strategy of residential centralized photovoltaic system in remote areas, Renewable Energy, 28: 997-1012.

7. Kolhe, M., S. Kolhe and J.C. Joshi, 2002. Economic viability of stand-alone solar photovoltaic system in comparison with dieselpowered system for India. Energy Economies 24: 155-165.

8. Wagdy, R.A., R.P. Mertens and R.Van Overstraeten, 1985. Economic feasibility of photovoltaic system in the developing countries. Solar wind Tech., 2 : 9-14.

9. Haas, R., 1995. The value of photovoltaic electicity for society. Solar Energy, 54: 25- 31. 